\title{
O orçamento-programa e a execução das políticas públicas
}

\author{
Flavio Rosendo dos Santos \\ Universidade Tecnológica Federal do Paraná (UTFPR)
}

Andréa Roseli Moreira Cruz Jankoski

Universidade Tecnológica Federal do Paraná (UTFPR)

Antonio Gonçalves de Oliveira

Universidade Tecnológica Federal do Paraná (UTFPR)

Vanessa Ishikawa Rasoto

Universidade Tecnológica Federal do Paraná (UTFPR)

O presente artigo tem por objetivo analisar o papel da técnica orçamento-programa na execução de políticas públicas no Estado brasileiro. Verificou-se que o orçamento público baseado em programas é um importante instrumento multidimensional de gestão, político e jurídico e de implementação de políticas públicas, expressando o planejamento dessas políticas que serão executadas pela administração pública. A metodologia utilizada foi pesquisa descritiva de cunho bibliográfico. Também é considerada quantitativa e qualitativa ex-post-facto, pois foram tratados dados orçamentário-financeiros no período de 2008 a 2013. Constatou-se que os recursos autorizados não foram executados integralmente, comparando-os com os recursos pagos. Conclui-se que as organizações da sociedade civil, os atores sociais e os grupos de interesse têm no orçamento-programa um importante instrumento de controle para cobrar da administração pública uma maior eficiência e efetividade nos gastos destinados aos programas de políticas públicas.

Palavras-chave: gestão orçamentária, orçamento público, gestão de políticas públicas, controle social

\section{Presupuesto por programas y implementación de políticas públicas}

Este artículo tiene como objetivo analizar el papel de la técnica del presupuesto por programas en la implementación de políticas públicas en el Estado brasileño. Se encontró que el presupuesto público basado en los programas es una importante herramienta multidimensional de gestión, política y jurídica y de la aplicación de políticas públicas, expresando la planificación de estas políticas a ser implementadas por el gobierno. La

[Artigo submetido em 25 de maio de 2015. Aprovado em 30 de novembro de 2016.] 
metodología utilizada fue de naturaleza descriptiva bibliográfica. También se considera cuantitativa y cualitativa ex-post-facto, ya que fueron tratados datos presupuestarios y financieros del período de 2008 a 2013. Se encontró que los fondos pagados en relación con los recursos autorizados no se aplicaron en su totalidad. Llegamos a la conclusión de que las organizaciones de la sociedad civil, actores sociales y grupos de interés tienen en el presupuesto un instrumento de control importante para cobrar del gobierno una mayor eficiencia y eficacia en el gasto destinado a programas de políticas públicas.

Palabras clave: gestión presupuestaria, presupuesto público, gestión de políticas públicas, control social

\section{Budget-program and implementation of public policies}

This article aims to analyze the role of technical program budget in the implementation of public policies in the Brazilian state. It was found that the public budget based on programs is an important multidimensional management tool, with political and legal scope, for the implementation of public policies, expressing the planning of these policies to be implemented by the government. The methodology used was of descriptive bibliographic nature. It is also considered quantitative and qualitative ex-post-facto, since were treated budgetary and financial data of the period 2008 to 2013. It was found that the authorized resources were not implemented in full, by comparing them with the paid funds. We conclude that the civil society organizations, social actors and interest groups have in the budget an important control instrument to charge the government greater efficiency and effectiveness in spending intended for public policy programs.

Keywords: budgetary management, public budget, public policy management, social control 


\section{Introdução}

O Estado exerce suas funções e busca atingir seus fins valendo-se da arrecadação e dispêndio de recursos ou receitas, as quais, no mais das vezes, são obtidas no seio da sociedade por ele governada mediante a cobrança de tributos, embora outras fontes não possam ser descartadas, tais como a exploração lucrativa de atividades econômicas, as rendas oriundas de seu patrimônio e os empréstimos.

Ao serem despendidas, de uma maneira ou de outra, as receitas arrecadadas retornam à sociedade da qual se originaram. Esse retorno pode se dar, por exemplo, pelos pagamentos efetuados a servidores públicos ou fornecedores, ou ainda, e mais especialmente, pela prestação de serviços públicos ou implementação de políticas públicas (PIRES; MOTTA, 2006).

Esse ciclo que envolve a arrecadação de receitas, a realização de despesas e a implementação de políticas públicas (objeto que interessa diretamente ao presente estudo) é permeado e intermediado pelo orçamento público, instrumento legislativo por meio do qual um Estado expressa suas escolhas financeiras num dado período (Assıs, 2009), isto é, identifica suas receitas e as despesas que realizará.

Despesas não autorizadas no orçamento não podem ser realizadas, de modo que políticas públicas não contempladas com recursos no orçamento não poderão ser efetivadas, como decorre do artigo 167, I, da Constituição Federal (BRASIL, 1988), que veda o início de programas ou projetos não previstos na lei orçamentária.

Portanto, políticas públicas e orçamento não são temas desconexos, embora, em sua concepção inicial, o orçamento público seja, antes de qualquer outra coisa, um instrumento de controle político, isto é, de fiscalização e controle do Poder Legislativo sobre o Poder Executivo e suas despesas, sem apresentar muita preocupação com as consequências dessas despesas (GIACOMONI, 2010).

Porém, modernamente, o orçamento público, de instrumento de autorização e controle pelo Legislativo, passou também a auxiliar na administração e planejamento, veiculando a programação do governo, suas metas e objetivos (GIACOMONI, 2010).

O orçamento público e as decisões orçamentárias passaram a ser direcionadas aos resultados - metas, objetivos, programas governamentais -, relacionando custos aos objetivos pretendidos, no que se convencionou chamar de orçamentoprograma (CAVALCANTE, 2007).

No Brasil, a concepção de orçamento não ficou imune a essa evolução, e a técnica do orçamento-programa também é adotada (ABREU, 2009), de modo que as políticas públicas porventura implementadas pelo Estado brasileiro serão previstas e manejadas, em termos orçamentários, de acordo com ditames dessa técnica. 
Nesse ponto reside a questão-problema que anima o presente estudo: quais as relações existentes entre o orçamento-programa e a execução de políticas públicas no Estado brasileiro, em especial no que se refere ao orçamento da União? Por consequência, o presente artigo objetiva analisar o papel da técnica orçamentoprograma na execução de políticas públicas no Estado brasileiro.

O resultado dessa pesquisa é o presente estudo, o qual se divide em seis seções, sendo a primeira esta introdução. Na segunda, é analisada a evolução do orçamento em direção ao orçamento-programa. A terceira seção é dedicada a analisar o conceito de orçamento-programa. A quarta seção explica a metodologia utilizada. A quinta seção dedica-se a analisar a execução orçamentária na implementação das políticas públicas. Na sexta e última seção, são apresentadas as considerações finais e extraídas as conclusões que se fizeram possíveis a partir do estudo realizado.

\section{Evolução do orçamento-programa}

Já se mencionou que o orçamento público é o instrumento por meio do qual o Estado expressa suas escolhas financeiras (Assıs, 2009). Nele, "o governo, de forma expressa ou indireta, decide sobre o papel que deve desempenhar e define prioridades" (CAVALCANTE, 2007, p. 129).

Porém, seu conceito - no qual se imbricam aspectos de ordem política, jurídica, contábil, econômica, financeira e administrativa - não ficou imune a modificações ao longo de sua história, evoluindo à medida que evoluíam suas funções (GIACOMONI, 2010).

Por tal motivo, Giacomoni (2010) propõe que a evolução conceitual do orçamento seja divida em duas fases: uma dita tradicional e outra chamada de moderna, as quais, como explica Couto (2009), constituem dois vértices extremos de uma linha do tempo da evolução orçamentária entre os quais estão presentes todas as espécies de orçamento público, sendo o orçamento moderno um ponto ideal e inalcançável, diante da constante incorporação de novos conceitos e técnicas a esse "ideal".

Para Pires e Motta (2006), as origens do orçamento estão vinculadas às origens do Estado de Direito, no que são acompanhados por Korff (1984, p. 09), para quem o surgimento do orçamento "se confunde com a origem dos próprios direitos do cidadão e das instituições de representação popular".

Nesse caminho, os antecedentes históricos do orçamento público remontam à Idade Média (Assıs, 2009) e às primeiras tentativas de limitar o poder discricionário dos soberanos na seara da tributação, atrelando-o à aceitação ou ao consentimento da sociedade. 
A partir daí, a formação da concepção tradicional de orçamento acompanha o crescimento do próprio Estado e as lutas políticas em torno do mesmo (PIRES; MotTA, 2006), isto é, a queda do Antigo Regime e a ascensão do Estado burguêsliberal, tendo o orçamento surgido, de acordo com Giacomoni (2010, p. 54), "como instrumento formalmente acabado, na Inglaterra, por volta de 1822".

Nesse período, sua função era precipuamente política, instrumento de controle do Poder Legislativo sobre o Executivo focado no equilíbrio financeiro, na contenção dos gastos públicos e na neutralidade da despesa pública, com poucas preocupações econômicas, de acordo com as concepções do Estado liberal (GIACOMONI, 2010).

Para o citado autor, esse orçamento tradicional caracterizava-se por não possuir preocupação com o planejamento dos órgãos estatais ou com os resultados esperados por eles ou deles esperados, por dar ênfase aos aspectos contábeis de gestão, por adotar critérios classificatórios baseados em unidades administrativas e elementos de despesa, pela inexistência de sistemas de medição dos resultados e por ter controle voltado para avaliar a legalidade da execução orçamentária, não seus resultados (GIACOMONI, 2010).

Todavia, o contínuo crescimento do Estado e de suas tarefas, acompanhado do crescimento das despesas públicas e das funções atribuídas a essas, com esteio em teorias keynesianas, bem como da necessidade de conferir maior racionalidade e eficiência às ações governamentais acabaram por enfraquecer o papel político do orçamento, dando maior prevalência a seus aspectos técnicos e abrindo caminho para novas técnicas orçamentárias, entre elas o orçamento-programa (KORFF, 1984).

Assim, de acordo com Pires e Motta (2006), no início do século 20, nos Estados Unidos, deu-se início à aproximação entre orçamento e planejamento. Nos anos 1930, o Departamento de Agricultura e a Administração do Vale do Tennessee adotou uma classificação orçamentária por projetos e programas. E, na década de 1940, a Comissão Hoover recomendou ao Governo Federal americano a adoção de orçamento que indicasse objetivos, custos e relação receita/despesa, estruturado em funções, projetos e atividades. No entanto, só em 1950, com a aprovação da Lei de Processo e Contabilidade, planejamento e orçamento foram integrados "a partir de uma concepção gerencial que procurava definir o orçamento como um elo de ligação entre o planejamento e as ações executivas da gestão pública e, para tanto, incorporava os custos dos programas do governo" (PIRES; MOTTA, 2006, p. 19). Tal concepção veio a ficar conhecida como Planning, Programming and Budget System (PBBS) (Sistema de Planejamento, Programação e Orçamento) e, segundo Cavalcante (2007), começou a ser abandonada em 1971, mas terminou por influenciar o que se convencionou chamar de orçamento-programa. 
O chamado orçamento-programa, tal qual sistematizado pela Organização das Nações Unidas (ONU) na década de 1960, com base no orçamento de desempenho proposto pela Comissão Hoover, com posterior adição de novos conceitos, alguns dos quais oriundos do PBBS, representa, para Giacomoni (2010), o ideal de orçamento moderno no Brasil.

Todavia, para Machado Júnior (2012), a concepção de orçamento-programa no Brasil está presente desde o Decreto-lei no 2146/40, o qual lançava bases para uma classificação funcional das finanças públicas, mas do qual não resultou "o florescimento promissor do orçamento-programa" (MACHADO JÚNIOR, 2012, p. 1157-1159), por falta de arcabouço teórico.

De acordo com Korff (1984), o orçamento-programa foi adotado no Brasil com a Lei no 4320/64. Machado Júnior (2012), porém, discorda dessa afirmação, embora admita que a referida lei abre margem às interpretações que favorecem o orçamento-programa.

Para Abreu (2009), embora o orçamento-programa já fosse formalmente utilizado pela administração pública, apenas no ano de 2000 ele foi adotado efetivamente, a partir de diversas medidas de reorganização do orçamento e planejamento federal, adotadas entre 1998 e 2000, a começar pelo Decreto $n$ ㅇ 2.829/98, culminando com a Lei de Responsabilidade Fiscal (Lei Complementar no 101/2000), as quais visavam permitir avaliações qualitativas e quantitativas das ações públicas.

A técnica do orçamento-programa continua a ser utilizada no Brasil (ABREU, 2009), como se pode extrair do próprio Plano Plurianual (PPA) (BRASIL, 2011) atualmente vigente (PPA 2012-2015), que se diz imbuído de uma concepção de planejamento e está estruturado em programas, por sua vez organizados em objetivos, os quais são detalhados em metas e iniciativas.

Essa é, em linhas gerais, a evolução do orçamento em direção ao orçamentoprograma, de instrumento do controle político de despesas a ferramenta de planejamento e avaliação das ações governamentais, como ficará mais claro no próximo tópico, quando seu conceito será investigado.

\section{Orçamento-programa: origem e características}

Após ter sido esclarecido o processo de evolução do orçamento tradicional em direção ao orçamento-programa, cumpre investigar mais detalhadamente o conceito de orçamento-programa, de modo a viabilizar a compreensão de seu papel na implantação e avaliação de políticas públicas.

De acordo com Rezende (1976, p. 42), o orçamento-programa diferencia-se dos métodos tradicionais de orçamento pela ênfase dada "no objetivo do gasto 
em vez da simples preocupação com a categoria de dispêndio". Não obstante, Ribeiro (2003, p. 4) não foca somente nos objetivos, ressaltando também o aspecto planejamento, pois para ele "o orçamento-programa não é apenas documento financeiro, mas, principalmente, instrumento de operacionalização das ações do governo, viabilizando seus projetos/atividades/operações especiais em consonância com os planos e diretrizes estabelecidos".

Nesse caminho, para Abreu (2009, p. 29), diante da complexidade característica dos Estados contemporâneos, cabe ao orçamento-programa a tarefa de veicular dados essenciais "para a programação e gestão orçamentária da Administração Pública, agregando informações em termos de espaço, dimensão temporal, forma de operar em relação a diversas unidades administrativas, bem como o efeito da despesa em relação aos objetivos programados".

Embora Burkhead (1971) diferencie orçamento de desempenho e orçamentoprograma, Giacomoni (2010), entendendo que a distinção perdeu seu significado com o passar do tempo, extrai do conceito de orçamento de desempenho dado por Burkhead (1971, p. 182-183) os elementos essenciais do orçamento-programa, a saber:

a) os objetivos e propósitos perseguidos pela instituição e para cuja consecução são utilizados os recursos orçamentários;

b) os programas, isto é, os instrumentos de integração dos esforços governamentais no sentido da concretização dos objetivos;

c) os custos dos programas medidos por meio da identificação dos meios ou insumos (pessoal, material, equipamentos, serviços etc.) necessários para a obtenção dos resultados; e

d) medidas de desempenho com a finalidade de medir as realizações (produto final) e os esforços despendidos na execução dos programas.

Nesse matiz, Giacomoni (2010) apresenta quadro síntese das características do orçamento-programa, a partir do qual é possível perceber que para ele o orçamentoprograma exerce o papel de elo entre planejamento e execução e que, segundo essa técnica, os recursos orçamentários são destinados não à aquisição de meios, mas ao atingimento de objetivos e metas. Além disso, as decisões orçamentárias devem ser tomadas a partir de avaliações e análises das alternativas possíveis, considerando-se todos os custos dos programas. O critério de classificação das despesas é funcionalprogramático, devendo ser utilizados instrumentos de medição do trabalho e dos resultados alcançados, pois o controle exercido deverá focar na eficiência, eficácia e efetividade das ações do Estado. 
A partir das mencionadas características do orçamento-programa, é possível perceber que essa técnica orçamentária é naturalmente direcionada a permitir um maior controle sobre as ações do Estado e os resultados de suas despesas, e não apenas sobre as despesas em si mesmas consideradas. Por inferência, essa técnica orçamentária permite um maior controle sobre as políticas públicas, papel a ser analisado na próxima seção.

\section{A relação entre políticas públicas e orçamento-programa}

Como visto, o orçamento-programa visa possibilitar um maior controle sobre as ações, objetivos, metas e resultados alcançados pelo Estado e pelas despesas por ele realizadas e, por extensão, possibilita também um maior controle sobre as políticas públicas por ele implantadas. Cumpre analisar mais detidamente esse papel.

De acordo com Abreu (2009, p. 28) o orçamento-programa pressupõe "a agregação de um conjunto de iniciativas públicas dentro de uma mesma unidade de gestão, que seria o programa, esses seriam operadores de opções de políticas públicas definidas pelos decisores de níveis estratégicos".

Por sua vez, na visão de Couto (2009), programas são instrumentos que integram esforços governamentais com vistas aos objetivos a serem alcançados, cujos custos devem ser mensurados com base nos insumos necessários à obtenção dos resultados, os quais, por sua vez, devem ser avaliados a partir de indicadores de desempenho.

Para Giacomoni (2010, p. 177), programa corresponde ao "campo em que se desenvolvem ações homogêneas que visam ao mesmo fim", e sua utilidade maior é propiciar aos escalões superiores análises e avaliações dessas ações (Giacomoni, 2010).

Pois bem, de acordo com Secchi (2012, p. 2), "política pública é uma diretriz elaborada para enfrentar um problema público", que passa pela tomada de decisões e envolve "diversas ações estrategicamente selecionadas para implementar as decisões tomadas" (RUA, 2009, p. 19).

Do ponto de vista político, "a formulação de políticas públicas constitui-se no estágio em que governos democráticos traduzem seus propósitos e plataformas eleitorais em programas e ações que produzirão resultados ou mudanças no mundo real" (SouZA, 2007, p. 69). Assim, o interior de um programa pode conter diversas políticas públicas, destinadas a dar atendimento aos múltiplos objetivos que compõem o programa.

Ora, segundo Ribeiro (2011, p.10), “o orçamento é o principal instrumento de realização de políticas públicas", e é no orçamento-programa que o Estado, 
por meio do seu Poder Executivo, prevê suas políticas destinando-Ihes receitas correspondentes às despesas necessárias à efetivação das mesmas. Sem previsão orçamentária não é possível implementar políticas públicas, como decorre do anteriormente citado artigo 167, I, da Constituição Federal (BRASIL, 1988).

Além disso, para Silva (2012, p. 28), “o orçamento é uma ferramenta de análise de políticas instrumentais ou setoriais a ser utilizada em conjunto com outras, conforme cada propósito de análise demandado" e, segundo Abreu (2009, p. 29), "como instrumento de análise de políticas públicas, o orçamento programa facilita a comparação dos custos e avaliação das alternativas que têm o mesmo objetivo".

Isso porque, conforme observa Giacomoni (2010), a mensuração das ações governamentais e de seus resultados é essencial no orçamento-programa e se dá pela instituição de um sistema que meça o rendimento do trabalho por meio do qual os objetivos politicamente escolhidos são buscados.

Para Bucci (2002), o que fundamenta a existência das políticas públicas no Brasil é o caráter de Estado social assumido pelo País, o qual, em razão disso, obrigase a uma atividade de concretização dos direitos fundamentais já positivados, entre os quais o direito à segurança. Nesse sentido, as políticas públicas podem ser definidas como as ações programadas pelo governo que visam "coordenar os meios à disposição do Estado e as atividades privadas, para a realização de objetivos socialmente relevantes e politicamente determinados", ou seja, as políticas públicas representam os instrumentos de ação dos governos (BUCCI, 2002, p. 135).

Em consequência, pode-se inferir que o orçamento-programa impõe a mensuração do rendimento das políticas públicas que compõem os diversos programas nos quais o orçamento está estruturado, contribuindo para a análise e avaliação das mesmas.

\section{Procedimentos metodológicos}

A fim de atingir os objetivos delineados, empreendeu-se uma pesquisa descritiva de cunho bibliográfico, pautada em livros, dissertações, monografias e artigos científicos pertinentes à temática, ao final referenciados.

Quanto à abordagem, trata-se de uma pesquisa quantitativa e qualitativa. Quantitativa, pois serão tratados dados orçamentário-financeiros no período de 2008 a 2013. Qualitativa, pois, a partir da análise dos dados classificados, fez-se possível identificar a execução orçamentária dos orçamentos estudados. Tratase também de uma pesquisa ex-post-facto, já que os orçamentos pesquisados ocorreram em anos passados. 
Registre-se que, para a viabilidade da comparação dos orçamentos temáticos de 2008 a 2013, os dados coletados foram ajustados pelo Índice Nacional de Preços ao Consumidor Amplo (IPCA), ano base 2013. Note-se ainda que, não obstante o amplo espectro dos programas, os orçamentos temáticos a serem estudados e analisados neste artigo são: Criança e Adolescente, Mulher, Meio Ambiente, Segurança Alimentar e Igualdade Racial.

O orçamento da União contém programas sociais do governo para diversas áreas de atuação, como saúde, educação e segurança alimentar, e para diversos grupos de beneficiários, como mulheres, crianças e quilombolas. Por meio de parcerias com organizações da sociedade civil que acompanham segmentos específicos das políticas públicas, identificam-se e destacam-se os diversos orçamentos temáticos contidos no orçamento da União. As informações dessas áreas se referem ao orçamento da União destinado às políticas que o Governo Federal desenvolve para combater o racismo e as desigualdades raciais; afetar diretamente a qualidade de vida e o desenvolvimento das crianças; e garantir os direitos das comunidades quilombolas e indígenas.

O orçamento temático da criança e do adolescente (OCA) é voltado para a promoção dos direitos humanos de crianças e adolescentes no Brasil. As principais áreas dizem respeito à promoção, proteção e defesa: políticas como educação, saúde, assistência social e programas voltados à promoção de direitos desse público específico, tais como Promoção dos Direitos de Criança e Adolescente, da Secretaria de Direitos Humanos (SDH).

O orçamento temático da mulher é um extrato do orçamento da União contendo as ações que, segundo a metodologia adotada, impactam a qualidade de vida das mulheres brasileiras. Foi organizado em parceria com o Centro Feminista de Estudos e Assessoria (CFEMEA), para facilitar o acompanhamento do processo orçamentário pelas entidades voltadas para as políticas da mulher.

O orçamento temático do meio ambiente é um extrato do orçamento da União contendo as ações que promovem a pesquisa, preservação, defesa e recuperação ambiental nos meios urbano e rural.

O orçamento temático da segurança alimentar é um extrato do orçamento da União contendo as ações que, segundo a metodologia adotada, promovem uma alimentação saudável, acessível, permanente e de qualidade para os cidadãos. Foi elaborado em parceria com o Instituto de Estudos Socioeconômicos (Inesc), para facilitar o acompanhamento do processo orçamentário pelas entidades integrantes do Conselho Nacional de Segurança Alimentar (Consea) e outras organizações da sociedade civil. 
O orçamento temático da igualdade racial busca realizar o monitoramento do orçamento das políticas públicas do Governo Federal voltadas para a promoção da igualdade racial e combate ao racismo. Fazem parte das políticas afirmativas programas, ações e planos orçamentários na área de educação e trabalho, de saúde, agricultura familiar, segurança alimentar, proteção do patrimônio histórico e promoção da cultura.

\section{Análise e discussão dos resultados}

Nesta seção, são realizadas as análises dos orçamentos temáticos de 2008 a 2013 referentes à lei orçamentária anual (LOA). Essa lei define o valor de dotações a que cada órgão faz jus ao longo do ano para realizar despesas. A análise se baseou no valor total anual de cada orçamento temático. Os dados foram coletados do SIGA Brasil, um sistema de informações sobre orçamento público que permite acesso amplo e facilitado aos dados do Sistema Integrado de Administração Financeira do Governo Federal (Siafi) e a outras bases de dados sobre planos e orçamentos públicos, por meio de uma única ferramenta de consulta, e agrupa os resultados em diferentes universos e objetos. Constam no SIGA Brasil as seguintes descrições para essas variáveis exploradas:

a) Dotação inicial: valor em reais discriminado na lei orçamentária anual (LOA) após ser sancionada pelo Presidente da República (já incluídos os vetos).

b) Autorizado: registra a soma dos valores da dotação inicial com os cancelamentos e remanejamentos relativos à abertura de créditos adicionais. Ex: Autorizado $=$ dotação inicial + créditos suplementares + créditos especiais + créditos extraordinários + dotação cancelada/remanejada.

c) Empenhado: soma dos empenhos a liquidar e liquidados.

d) Pago: indica os valores pagos e corresponde ao terceiro e último estágio da despesa.

A seguir, traz-se ao plano um histórico dos recursos orçamentários autorizados (ou seja, previstos para determinado ano) em contraste com os recursos efetivamente liquidados e pagos para as ações orçamentárias. Na execução orçamentária das políticas públicas, a fase de liquidação é o momento em que a administração pública reconhece que o serviço foi prestado ou o bem foi entregue. A fase seguinte é a do pagamento, em que se quitam os débitos relacionados à despesa liquidada. Nem sempre o pagamento é concomitante à liquidação: o governo pode pagar em momento posterior ou até mesmo no ano seguinte (configurando os "restos a pagar"). A observação desses dados permite fazer algumas inferências. 
Em primeiro lugar, nota-se que raras vezes a execução da política é integral: observa-se que em nenhum ano a execução atingiu $100 \%$ dos valores previstos. Em 2008, executou-se 98,43\% dos recursos autorizados, e nos demais anos, a liquidação ficou numa média de 88,09\%, limitando-se ao máximo de 95,35\% em 2011 e ao mínimo de 79,21\% em 2012. A média de crescimento foi de 5\% dos recursos autorizados em relação ao previsto inicialmente, no período de 2008 a 2013 (Tabela 1).

Em 2013, os programas e ações que correspondem ao orçamento criança e adolescente representaram $\mathrm{R} \$ 105$ bilhões. Do total autorizado (R\$ 105 bilhões), foram empenhados, ou seja, foram comprometidos com a realização de despesas R\$ 98 bilhões, significando 93,2\%, porém, os recursos pagos representaram $79,88 \%$ (Tabela 1).

Tabela 1 - Orçamento da criança e do adolescente

\begin{tabular}{c|c|c|c|c|c|cc}
\hline \multicolumn{2}{|c|}{} & & & ciquidado & R\$ 1,00 \\
\hline Ano & Dotação inicial & Autorizado & Empenhado & $\begin{array}{c}\text { Pago } \\
\text { (subelemento) }\end{array}$ & $\begin{array}{c}\text { \%Execução } \\
\text { (liq./aut.) }\end{array}$ & $\begin{array}{c}\text { \%ecução } \\
\text { (pago/ } \\
\text { aut.) }\end{array}$ \\
\hline 2008 & 55.871 .404 .811 & 57.576 .442 .508 & 56.675 .125 .836 & 56.675 .059 .689 & 52.411 .844 .817 & $98,43 \%$ & $91,03 \%$ \\
2009 & 65.635 .241 .167 & 67.241 .304 .491 & 60.501 .473 .329 & 60.501 .473 .329 & 56.225 .691 .168 & $89,98 \%$ & $83,62 \%$ \\
2010 & 69.238 .640 .329 & 71.991 .699 .931 & 68.344 .440 .909 & 68.344 .440 .909 & 62.263 .768 .072 & $94,93 \%$ & $86,49 \%$ \\
2011 & 75.837 .305 .499 & 82.490 .668 .138 & 78.654 .371 .975 & 78.654 .371 .975 & 71.164 .704 .402 & $95,35 \%$ & $86,27 \%$ \\
2012 & 90.510 .566 .703 & 97.798 .694 .287 & 88.092 .198 .088 & 77.469 .535 .092 & 77.403 .798 .270 & $79,21 \%$ & $79,15 \%$ \\
2013 & 100.814 .742 .299 & 105.233 .812 .046 & 98.028 .409 .579 & 85.241 .022 .131 & 84.057 .040 .340 & $81,00 \%$ & $79,88 \%$ \\
\hline
\end{tabular}

Fonte: SIGA Brasil, Senado Federal.

Obs.: Valores atualizados pelo IPCA/IBGE, ano base 2013.

Além disso, parece haver um descompasso entre os momentos da liquidação e do pagamento, visto que os montantes pagos são, geralmente, inferiores aos montantes liquidados. Isso indica que, em praticamente todos os anos, o governo executou, mas não pagou as despesas, resultando na acumulação de montantes (os chamados "restos a pagar") para pagamento nos anos seguintes, o que configura uma espécie de "orçamento paralelo", que pode prejudicar e até inviabilizar a execução de políticas em anos posteriores.

Em 2013, dos 17 programas que compõem o orçamento criança e adolescente foram elencados os dez que tiveram melhor desempenho em relação aos recursos empenhados: Bolsa Família - 99,95\% (R\$ 24 bilhões); Operações Especiais: 
Transferências Constitucionais e as Decorrentes de Legislação Específica 95,58\% (R\$ 39 bilhões); Fortalecimento do Sistema Único de Assistência Social - 92,87\% (R\$ 2 bilhões); Educação Básica - 89,81\% (R\$ 28 bilhões); Reforma Agrária e Ordenamento da Estrutura Fundiária - 88,99\% (27 milhões); Proteção e Promoção dos Direitos dos Povos Indígenas - 81,69\% (R\$ 44 milhões); Promoção dos Direitos de Crianças e Adolescentes - 81,62\% (R\$ 417 milhões); Trabalho, Emprego e Renda - 80,64\% (R\$ 27 milhões); Promoção e Defesa dos Direitos Humanos - 71,92\% (R\$ 76 milhões); e Esporte e Grandes Eventos Esportivos 69,51\% (R\$ 1 milhão) (Gráfico 1).

Gráfico 1 - Programas com melhores recursos empenhados (orçamento criança e adolescente), 2013

\section{Orçamento Criança e Adolescente}

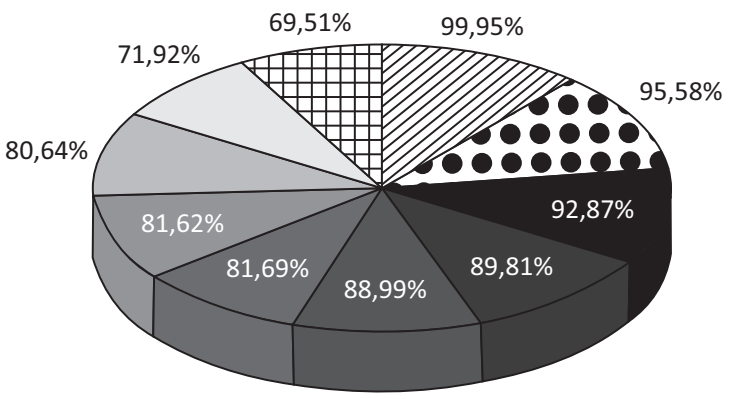

Bolsa Família

\# Operações Especiais: Transferências Constitucionais e as Decorrentes de Legislação Específica

Fortalecimento do Sistema Único de Assistência Social

Educação Básica

Reforma Agrária e Ordenamento da Estrutura Fundiária

Proteção e Promoção dos Direitos dos Povos Indígenas

Promoção dos Direitos de Crianças e Adolescentes

Trabalho, Emprego e Renda

Promoção e Defesa dos Direitos Humanos

::: Esporte e Grandes Eventos Esportivos

Fonte: Elaboração própria a partir do SIGA Brasil, Senado Federal, 2013.

Na Tabela 2, observa-se que em 2008 executou-se 90,87\% dos recursos autorizados, e nos demais anos, a liquidação ficou numa média de 83,38\%. Em 2013, os programas e ações que correspondem ao orçamento mulher representaram $\mathrm{R} \$$ 
171 bilhões. Do total autorizado (R\$ 171 bilhões), foram empenhados, ou seja, foram comprometidos com a realização de despesas $\mathrm{R} \$ 154$ bilhões, significando $90,1 \%$. Mas só foram efetivamente realizadas despesas que representam $68,7 \%$ do total autorizado e pagos 67,5\%. Isso significa que cerca de $\mathrm{R} \$ 37$ bilhões que se referem às despesas empenhadas em 2013 só serão efetivamente realizadas nos exercícios seguintes, devido principalmente aos limites impostos para pagamento das despesas do exercício vigente e de restos a pagar de outros anos, definidos no decreto de programação financeira do Governo Federal.

Nota-se também que o percentual médio de aumento do recurso autorizado em relação à dotação inicial foi de $6 \%$, no período analisado.

Tabela 2 - Orçamento mulher

\begin{tabular}{c|c|c|c|c|c|c|c}
\hline \multicolumn{2}{|c|}{} & & & & & & \\
Liquidado & 1,00 \\
\hline Ano & Dotação inicial & Autorizado & Empenhado & $\begin{array}{c}\text { Liquecução } \\
\text { (subelemento) }\end{array}$ & $\begin{array}{c}\text { \%Execução } \\
\text { (pago/ } \\
\text { aut.) }\end{array}$ \\
\hline 2008 & 103.888 .150 .496 & 110.887 .345 .279 & 100.761 .074 .033 & 100.760 .984 .869 & 82.234 .884 .381 & $90,87 \%$ & $74,16 \%$ \\
2009 & 111.928 .735 .693 & 116.931 .245 .277 & 109.986 .204 .255 & 109.986 .204 .255 & 86.837 .083 .470 & $94,06 \%$ & $74,26 \%$ \\
2010 & 116.201 .236 .632 & 120.336 .230 .716 & 110.000 .809 .092 & 110.000 .809 .092 & 91.934 .865 .393 & $91,41 \%$ & $76,40 \%$ \\
2011 & 121.444 .713 .890 & 129.757 .226 .682 & 120.186 .716 .750 & 120.186 .716 .750 & 98.467 .532 .592 & $92,62 \%$ & $75,89 \%$ \\
2012 & 156.098 .897 .253 & 169.791 .420 .014 & 147.723 .984 .002 & 119.042 .898 .151 & 118.561 .987 .965 & $70,11 \%$ & $69,83 \%$ \\
2013 & 163.337 .217 .128 & 171.034 .488 .803 & 154.063 .776 .851 & 117.478 .032 .439 & 115.428 .284 .814 & $68,69 \%$ & $67,49 \%$ \\
\hline
\end{tabular}

Fonte: SIGA Brasil, Senado Federal.

Obs.: Valores atualizados pelo IPCA/IBGE, ano base 2013.

Em 2013, dos 40 programas que compõem o orçamento mulher, foram selecionados os dez que tiveram melhor desempenho em relação aos recursos empenhados: Bolsa Família - 99,95\% (R\$ 24 bilhões); Moradia Digna - 99,29\% (R\$ 15 bilhões); Educação Básica - 92,21\% (R\$ 25 bilhões); Fortalecimento do Sistema Único de Assistência Social - 91,67\% (R\$ 2 bilhões); Aperfeiçoamento do Sistema Único de Saúde - 91,46\% (R\$ 58 bilhões); Saneamento Básico - 91,29\% (R\$ 584 milhões); Cidadania e Justiça - 89,90\% (R\$ 134 milhões); Proteção e Promoção dos Direitos dos Povos Indígenas - 89,86\% (R\$ 1 bilhão); Democracia e Aperfeiçoamento da Gestão Pública - 88,82\% (R\$ 290 milhões); e Educação Profissional e Tecnológica $-84,75 \%$ (R\$ 5 bilhões) (Gráfico 2). 
Gráfico 2 - Programas com melhores recursos empenhados (orçamento mulher), 2013

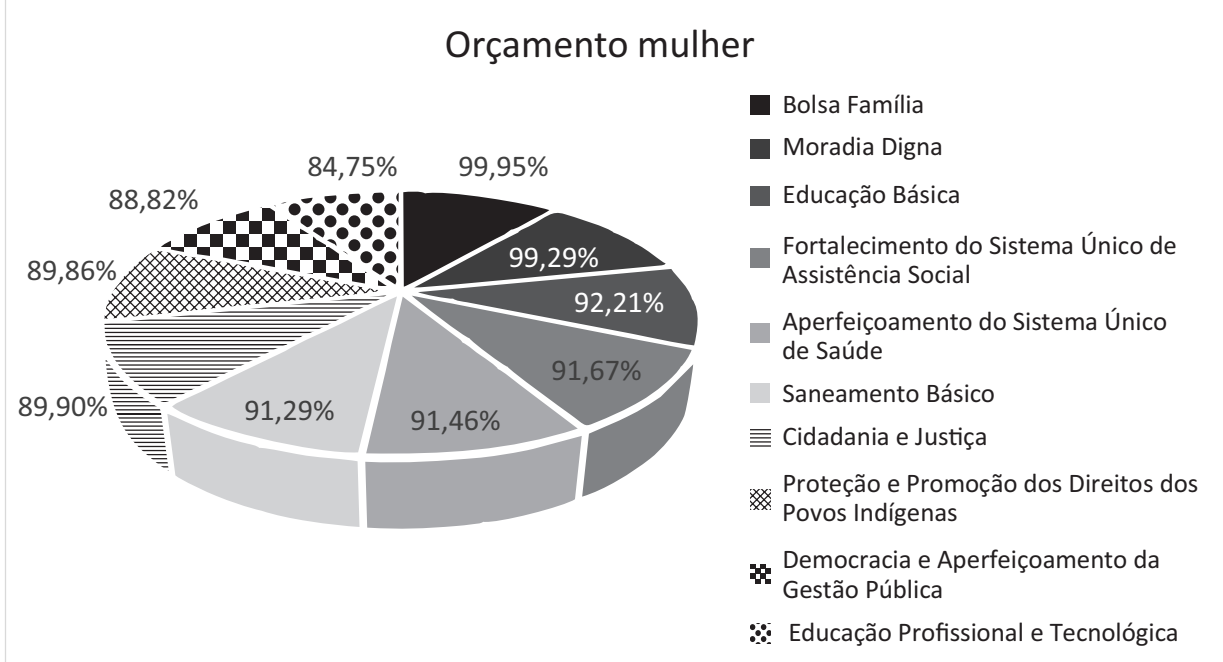

Fonte: Elaboração própria a partir do SIGA Brasil, Senado Federal, 2013.

A Tabela 3, sobre o orçamento do Ministério do Meio Ambiente, mostra-se mais equilibrada em relação ao que foi liquidado nos anos 2008 a 2013 (média de $51,49 \%$ ) e os valores pagos (média de $48,62 \%$ ), porém os valores liquidados e pagos ficaram abaixo do previsto em relação aos recursos autorizados. A média de crescimento entre o recurso inicial (dotação inicial) e o recurso autorizado foi de $7 \%$, no período. Porém, percebe-se uma pequena queda no ano de 2009 (-0,26\%). Em compensação, em 2011 houve um aumento de 11\%, do autorizado em relação ao que foi previsto.

Tabela 3 - Orçamento do Ministério do Meio Ambiente

\begin{tabular}{c|c|c|c|c|c|c|c}
\hline \multicolumn{2}{c}{ R } & \multicolumn{1}{c}{ R 1,00 } \\
\hline Ano & Dotação inicial & Autorizado & Empenhado & $\begin{array}{c}\text { Liquidado } \\
\text { (subelemento) }\end{array}$ & Pago & $\begin{array}{c}\text { \%Execução } \\
\text { (liq./aut.) }\end{array}$ & $\begin{array}{c}\text { \%Execução } \\
\text { (pago/aut.) }\end{array}$ \\
\hline 2008 & $4.124 .827 .531,85$ & 4.411 .905 .057 & 2.148 .197 .781 & 2.148 .197 .781 & 1.992 .164 .217 & $48,69 \%$ & $45,15 \%$ \\
2009 & $4.659 .198 .466,74$ & 4.646 .891 .571 & 2.211 .085 .002 & 2.211 .085 .002 & 2.048 .727 .516 & $47,58 \%$ & $44,09 \%$ \\
2010 & $4.452 .799 .236,46$ & 4.895 .046 .827 & 2.487 .862 .676 & 2.487 .862 .676 & 2.298 .758 .749 & $50,82 \%$ & $46,96 \%$ \\
2011 & $3.986 .067 .841,10$ & 4.421 .188 .871 & 2.702 .454 .161 & 2.702 .454 .161 & 2.446 .383 .416 & $61,13 \%$ & $55,33 \%$ \\
2012 & $4.150 .095 .916,05$ & 4.411 .271 .224 & 2.659 .698 .183 & 2.313 .088 .032 & 2.302 .574 .498 & $52,44 \%$ & $52,20 \%$ \\
2013 & $4.456 .461 .899,00$ & 4.695 .275 .887 & 2.563 .017 .520 & 2.267 .482 .777 & 2.252 .969 .280 & $48,29 \%$ & $47,98 \%$ \\
\hline
\end{tabular}

Fonte: SIGA Brasil, Senado Federal.

Obs.: Valores atualizados pelo IPCA/IBGE, ano base 2013. 
Selecionaram-se os dez programas do orçamento do Ministério do Meio Ambiente com melhor efetividade no tocante aos recursos empenhados em relação aos recursos autorizados: Ciência, Tecnologia e Inovação - 100,00\% (R\$ 2 milhões); Educação Superior: Graduação, Pós-Graduação, Ensino, Pesquisa e Extensão - 100,00\% (R\$ 594 mil); Segurança Alimentar e Nutricional - 99,90\% (R\$ 90 milhões); Previdência de Inativos e Pensionistas da União - 99,53\% (R\$ 367 milhões); Programa de Gestão e Manutenção do Ministério do Meio Ambiente 96,67\% (R\$ 1 bilhão); Operações Especiais: Cumprimento de Sentenças Judiciais - 95,40\% (R\$ 26 milhões); Proteção e Promoção dos Direitos dos Povos Indígenas - 91,05\% (R\$ 182 mil); Conservação e Gestão de Recursos Hídricos - 86,72\% (R\$ 258 milhões); Florestas, Prevenção e Controle do Desmatamento e dos Incêndios - 70,91\% (R\$ 228 milhões); Licenciamento e Qualidade Ambiental - 64,81\% (R\$ 21 milhões) (Gráfico 3).

\section{Gráfico 3 - Programas com melhores recursos empenhados (orçamento do Ministério do Meio Ambiente), 2013}
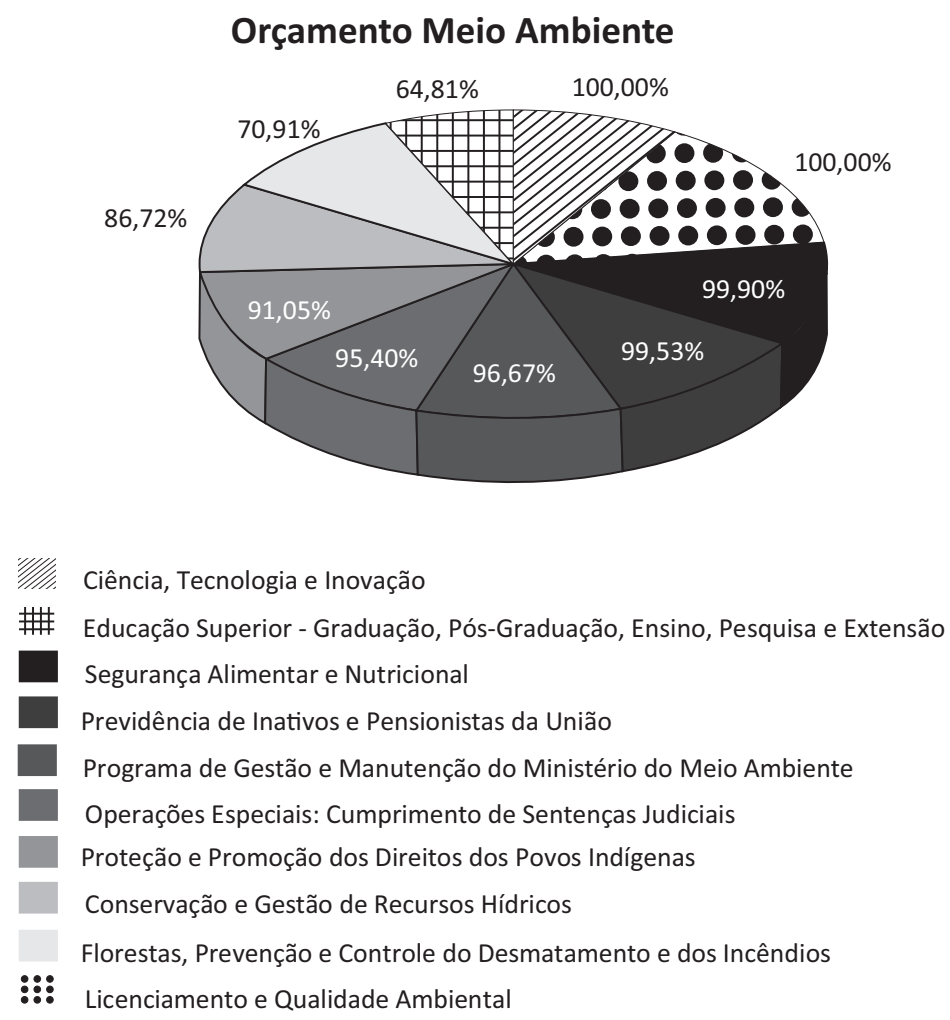
A Tabela 4, sobre o orçamento da segurança alimentar, também revela que a execução orçamentária ficou abaixo dos 100\%. Somente no ano de 2009 a liquidação dos valores chegou a 92,76\%, e, comparando com o que foi efetivamente pago, a situação piora, pois ficou em torno de $79,73 \%$. A média dos outros anos foi $81,55 \%$ e $72,39 \%$ entre os valores liquidados e os valores pagos, respectivamente.

Em 2011, o orçamento segurança alimentar obteve um aumento de 19\% no recurso autorizado em relação ao recurso previsto na lei orçamentária. A média do período ficou em torno dos $10 \%$.

Em 2012, os recursos autorizados corresponderam a 45 bilhões de reais, mas foram efetivamente pagos 30 bilhões (67,53\%) e liquidados em torno de $68,03 \%$ (R\$31 bilhões). Em relação ao ano de 2013, não constam dados no Sistema SIGA Brasil para consulta.

Tabela 4 - Orçamento segurança alimentar

\begin{tabular}{c|c|c|c|c|c|c|c}
\hline \multicolumn{7}{c}{ R\$ 1,00 } \\
\hline Ano & Dotação inicial & Autorizado & Empenhado & $\begin{array}{c}\text { Liquidado } \\
\text { (subelemento) }\end{array}$ & $\begin{array}{c}\text { Pago } \\
\text { \%Execução } \\
\text { (liq./aut.) }\end{array}$ & $\begin{array}{c}\text { \%Execução } \\
\text { (pago/aut.) }\end{array}$ \\
\hline 2008 & 31.802 .423 .155 & 33.152 .522 .029 & 26.657 .939 .290 & 26.657 .934 .377 & 23.167 .321 .142 & $80,41 \%$ & $69,88 \%$ \\
2009 & 31.874 .948 .299 & 34.048 .577 .796 & 31.584 .885 .080 & 31.584 .885 .080 & 27.145 .938 .334 & $92,76 \%$ & $79,73 \%$ \\
2010 & 32.640 .817 .507 & 35.254 .352 .332 & 30.694 .654 .663 & 30.694 .654 .663 & 26.678 .706 .196 & $87,07 \%$ & $75,67 \%$ \\
2011 & 32.602 .448 .112 & 38.802 .232 .746 & 35.192 .820 .824 & 35.192 .820 .824 & 29.666 .881 .068 & $90,70 \%$ & $76,46 \%$ \\
2012 & 40.871 .797 .335 & 45.802 .035 .997 & 38.656 .749 .772 & 31.160 .555 .866 & 30.932 .301 .903 & $68,03 \%$ & $67,53 \%$ \\
\hline
\end{tabular}

Fonte: SIGA Brasil, Senado Federal.

Obs.: Valores atualizados pelo IPCA/IBGE, ano base 2013.

Os dados do ano de 2013 não estão disponíveis no SIGA Brasil.

A situação é semelhante no orçamento da igualdade racial. Como se vê na Tabela 5, a execução nos anos 2008 a 2010 é muito diferente considerando-se os valores liquidados (média de 48,42\%) e os valores pagos (média de $12,24 \%$ ) em relação aos valores autorizados.

Comparando os dados dos recursos autorizados e da dotação inicial, em 2012 ocorreu um aumento substancial em torno dos 39\%, no entanto, nos anos de 2010 e 2013 , houve queda equivalente a $-4,2 \%$ e $-0,4 \%$, respectivamente. A média no período ficou aproximadamente $13,4 \%$, sendo assim, o orçamento igualdade racial, em comparação aos outros orçamentos acima, foi o que teve a maior média de aumento no período considerado, mas em compensação sua execução ficou muito aquém do esperado.

Em 2013, os recursos autorizados representaram 2 bilhões de reais, mas somente $14,80 \%$ dos recursos foram pagos ( $R \$ 345$ milhões). 
Tabela 5 - Orçamento igualdade racial

\begin{tabular}{c|c|c|c|c|c|c|c}
\hline \multicolumn{7}{c}{ R\$ 1,00 } \\
\hline Ano & Dotação inicial & Autorizado & Empenhado & $\begin{array}{c}\text { Liquidado } \\
\text { (subelemento) }\end{array}$ & Pago & $\begin{array}{c}\text { \%Execução } \\
\text { (liq./aut.) }\end{array}$ & $\begin{array}{c}\text { \%Execução } \\
\text { (pago/aut.) }\end{array}$ \\
\hline 2008 & 245.337 .333 & 275.042 .242 & 160.812 .377 & 160.809 .584 & 11.037 .044 & $58,47 \%$ & $4,01 \%$ \\
2009 & 264.355 .778 & 345.254 .522 & 239.381 .927 & 239.381 .927 & 27.030 .026 & $69,33 \%$ & $7,83 \%$ \\
2010 & 321.308 .794 & 307.854 .461 & 224.104 .841 & 224.104 .841 & 51.506 .113 & $72,80 \%$ & $16,73 \%$ \\
2011 & 277.303 .745 & 285.091 .380 & 165.205 .395 & 165.205 .395 & 45.073 .991 & $57,95 \%$ & $15,81 \%$ \\
2012 & 1.600 .132 .752 & 2.234 .474 .737 & 971.475 .025 & 345.438 .842 & 318.190 .822 & $15,46 \%$ & $14,24 \%$ \\
2013 & 2.341 .954 .638 & 2.333 .042 .698 & 1.152 .568 .649 & 385.166 .467 & 345.293 .798 & $16,51 \%$ & $14,80 \%$ \\
\hline
\end{tabular}

Fonte: SIGA Brasil, Senado Federal.

Obs.: Valores atualizados pelo IPCA/IBGE, ano base 2013.

Em 2013, foram selecionados seis programas do orçamento igualdade racial com melhor efetividade no tocante aos recursos empenhados em relação aos recursos autorizados: Aperfeiçoamento do Sistema Único de Saúde - 89,20\% (R\$ 51 milhões); Política Externa - 78,95\% (R\$ 1 milhão); Licenciamento e Qualidade Ambiental 75,85\% (R\$ 265 mil); Enfrentamento ao Racismo e Promoção da Igualdade Racial - 74,60\% (R\$ 56 milhões); Segurança Alimentar e Nutricional - 71,25\% (R\$ 228 milhões); e Biodiversidade - 64,16\% (R\$ 58 milhões).

\section{Gráfico 4 - Programas com melhores recursos empenhados (orçamento igualdade racial), 2013}

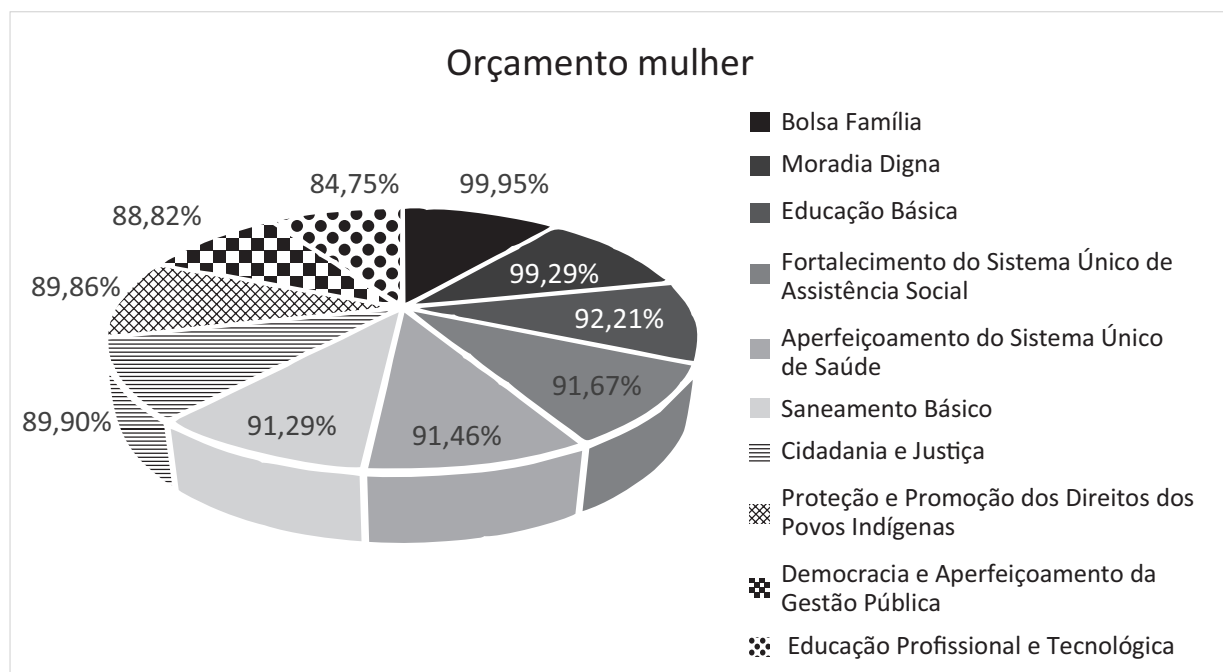

Fonte: Elaboração própria a partir do SIGA Brasil, Senado Federal, 2013. 
Longe de serem novidade, essas constatações há muito são discutidas entre estudiosos/as da temática: Pereira e Reis (2011), citando Diane Elson (2002, p. 4), apontam que frequentemente existem importantes brechas entre o planejado e o executado em termos de recursos públicos. Isso pode ser um indicativo de falta de prioridade a essas políticas públicas, ou mesmo um indicador da (in)capacidade técnica e administrativa do governo (ANDía; BELTRÁN, 2003).

\section{Considerações finais}

O orçamento público baseado em programas é um importante instrumento multidimensional de gestão, político e jurídico e de implementação de políticas públicas, expressando o planejamento dessas políticas que serão colocadas em execução pela administração pública.

No mais, o orçamento por programas representou um importante passo no aprimoramento da programação das despesas, pois passou a ser um instrumento de operacionalização das ações do governo, em conformidade com os planos e diretrizes formulados no planejamento estratégico.

Este estudo não analisou detalhadamente a execução orçamentária dos programas e ações dispostos nos orçamentos temáticos, mas sim avaliou o volume global dos recursos autorizados, liquidados e pagos no período compreendido entre 2008 a 2013. Entretanto, foram mencionados os programas com maior desempenho em relação aos recursos empenhados sobre os recursos autorizados no ano de 2013, de acordo com os orçamentos temáticos.

Verificou-se que nem toda dotação empenhada foi efetivamente liquidada. Isso se justifica porque a dotação é uma mera autorização de gasto a partir da fixação da despesa. Importa notar que a lei orçamentária é uma autorização de gastos, mas não uma obrigação de gastos. Por isso o orçamento é dito autorizativo e não impositivo.

Além disso, a constatação obtida ao analisar os orçamentos temáticos do Governo Federal - em que se encontram os programas e ações para políticas públicas específicas como o orçamento mulher, orçamento criança e adolescente, orçamento da Secretaria do Meio Ambiente, orçamento igualdade racial e orçamento segurança alimentar - é que não foram executados em sua totalidade, talvez pela ineficiência dos gestores públicos ou por falta de interesse político por parte do governo, ou ainda porque os recursos arrecadados não foram suficientes para contemplar os programas e ações previstos.

Nota-se, porém, que o orçamento mulher e o orçamento criança e adolescente foram os mais efetivos na execução orçamentária em relação ao recurso pago e 
autorizado do montante total, ou seja, em média ficou em torno de $73 \%$ e $84 \%$, respectivamente, no período analisado (2008 a 2013). Já o orçamento do Ministério do Meio Ambiente e o orçamento igualdade racial foram os mais ineficientes, pois na média foram executados somente $48 \%$ e $12 \%$, respectivamente, no período estudado (2008 a 2013).

A partir desses dados é possível inferir, respondendo ao problema inicialmente proposto, que a técnica de orçamento-programa empregada no Brasil permite visualizar, do ponto de vista orçamentário (da previsão e execução de despesas), o grau de realização dos programas e, por consequência, das políticas públicas neles compreendidas, revelando um descompasso entre o inicialmente planejado e o efetivamente realizado, entre as despesas previstas e autorizadas pela lei orçamentária e as despesas liquidadas, entre as políticas públicas contempladas com recursos no momento da elaboração da lei orçamentária e as políticas públicas implementadas mediante o efetivo dispêndio dos recursos destinados a elas.

Dessa forma, as organizações da sociedade civil, os atores sociais e os grupos de interesse têm aí um importante instrumento de controle para cobrar da administração pública uma maior eficiência e efetividade nos gastos destinados aos programas de políticas públicas. Assim, a participação social na estruturação do orçamento público e no acompanhamento de sua execução se faz indispensável para que os recursos necessários à realização das políticas públicas sejam incluídos no orçamento, bem como para que, uma vez reservados, sejam aplicados ao destino previsto, no contexto de uma apropriada execução orçamentária.

\section{Referências bibliográficas}

ABREU, Cilair Rodrigues de. A produção de informação no contexto do orçamentoprograma: uma análise a partir das informações contidas no cadastro de ações orçamentárias do governo federal. 2009. 96 f. Dissertação (Mestrado em Administração) - Universidade de Brasília - Faculdade de Economia, Administração, Contabilidade e Ciência da Administração, Brasília, 2009. Disponível em: <http:// repositorio.unb.br/bitstream/10482/3937/1/2009_CilairRodriguesdeAbreu.pdf> Acesso em: 22 nov 2014.

AssIS, Luiz Gustavo Bambini de. Processo legislativo e orçamento público: a função de controle do parlamento. 2009. 299 f. Tese (Doutorado em Direito do Estado) Universidade de São Paulo - Faculdade de Direito, São Paulo, 2009.

AndíA, B.; Beltrán, A. (2003). Documento Metodológico sobre el Análisis Del Presupuesto Público con Enfoque de Género: sistematización de las experiencias en la Región Andina. Unifem Andina, 2003. Disponível em: http:// www.gender-budgets.org/index.php?option $=c o m \_j o o m d o c \& t a s k=d o c \_$ download\&gid=107\&ltemid=189. Acesso em: 06 dez. 2014. 
BRASIL, Constituição (1988). Constituição da República Federativa do Brasil de 1988. Disponível em <http://www.planalto.gov.br/ccivil_03/constituicao/Constituicao Compilado.htm> Acesso em: 22 nov. 2014.

BRASIL. Ministério do Planejamento, Orçamento e Gestão. Secretaria de Planejamento e Investimentos Estratégicos. Plano Plurianual 2012-2015: projeto de lei. Brasília, 2011. Disponível em <http://www.planejamento.gov.br/secretarias/ upload/Arquivos/spi/PPA/2012/mp_003_modelo_planeja_gov.pdf> Acesso em: 25 nov. 2014.

Buccl, Maria Paula Dallari. Direito administrativo e políticas públicas. São Paulo: Saraiva, 2002.

BURKHEAD, Jesse. Orçamento público. Rio de Janeiro: FGV, 1971.

CAVAlCANTE, Pedro Luiz. O plano plurianual: resultados da mais recente reforma do planejamento e orçamento no Brasil. Revista do Serviço Público, Brasília, v. 58, n. 2, p. 129-150, 2007. Disponível em: <http://seer.enap.gov.br/index.php/RSP/article/ view/168/173> Acesso em: 22 nov. 2014.

Couto, Luciana Torres da Silveira Graça. O orçamento público e a evolução da eficiência do gasto público no Brasil. 2009. 101 f. Dissertação (Mestrado em Economia do Setor Público) - Universidade de Brasília, Brasília, 2009. Disponível em: <http://repositorio.unb.br/bitstream/10482/9883/1/2009_ LucianaTorresSilveiraGracaCouto.pdf> Acesso em: 24 nov. 2014.

GIAcomoni, James. Orçamento público. 15 ed. ampl., rev. e atual. São Paulo: Atlas, 2010.

KORFF, Eurico. O disciplinamento da gestão financeira do poder público. Revista de Administração de Empresas, São Paulo, v. 24, n. 3, p. 09-17, 1984. Disponível em: <http://www.scielo.br/scielo.php?pid=S0034-75901984000300003\&script=sci_ arttext> Acesso em: 24 nov. 2014.

MACHADO JÚNIOR, José Teixeira. A experiência brasileira em orçamento-programa - uma primeira visão. Revista de Administração Pública, Rio de Janeiro, v. 46, n. 4, p. 1157-1175, 2012. Disponível em: <http://www.scielo.br/scielo.php?pid=S003476122012000400012\&script=sci_arttext> Acesso em: 24 nov. 2014.

PIRES, José Santo Dal Bem; MotTA, Walmir Francelino. A evolução histórica do orçamento público e sua importância para a sociedade. Enfoque: Reflexão Contábil, Maringá, v. 25, n. 2, p. 16-25, 2006. Disponível em: <http://www.periodicos.uem. br/ojs/index.php/Enfoque/article/view/3491/3158> Acesso em: 24 nov. 2014.

REZENDE, Fernando. Orçamento-programa a nível empresarial. Revista de Administração de Empresas, Rio de Janeiro, v. 16, n. 2, p. 42-51, 1976. Disponível em: <http://rae.fgv.br/sites/rae.fgv.br/files/artigos/10.1590_S003475901976000200005.pdf> Acesso em: 26 nov. 2014.

Ribeiro, Maria de Fatima. Efetivação de políticas públicas e a escassez de recursos financeiros. Âmbito Jurídico, Rio Grande, v. 14, n. 93, 2011. Disponível em: <http://www.ambito-juridico.com.br/site/index.php?n_link=revista_artigos_ leitura\&artigo_id=10522>. Acesso em: 29 nov. 2014. 
RIBEIRo, Renato Jorge Brown. Possibilidades de transformações no sistema de planejamento e orçamento no Brasil. In: CONGRESO INTERNACIONAL DEL CLAD SOBRE LA REFORMA DEL ESTADO Y DE LA ADMINISTRACIÓN PÚBLICA, 8., 2003, Panamá. Disponível em: < http://siare.clad.org/fulltext/0047310.pdf >. Acesso em: 26 nov. 2014.

PereIRA, Ana Claudia Jaquetto; ReIS, Sarah de Freitas. Subjetividades e gênero nas políticas de saúde para promoção dos direitos reprodutivos: uma análise das construções discursivas e da execução orçamentária, 2011. In: Anais do II Simpósio Gênero e Políticas Públicas, 2., 2011, Universidade Estadual de Londrina, Londrina. Disponível em: <http://www.uel.br/eventos/gpp/pages/arquivos/Ana\%20Claudia \%20e\%20cia.pdf>. Acesso em: 06 dez. 2014.

RuA, Maria das Graças. Políticas públicas. Florianópolis: Departamento de Ciências da Administração/UFSC; Brasília: Capes: UAB, 2009.

SECCHI, Leonardo. Políticas públicas: conceitos, esquemas de análise, casos práticos. São Paulo: Cengage Learning, 2012.

Senado Federal. SIGA Brasil. LOA - Despesa Execução: Orçamento Mulher, Orçamento Criança e Adolescente, Orçamento do Ministério do Meio Ambiente, Orçamento Segurança Alimentar e Orçamento Igualdade Racial. Disponível em: <www.sigabrasil.gov.br>. Acesso em: 02 dez. 2014.

Silva, Priscilla Teresinha Pyrrho de Souza. O orçamento público como ferramenta de análise de políticas públicas. 2012. 153 f. Monografia (Especialização em Orçamento Público) - Instituto Serzedello Corrêa do Tribunal de Constas da União, Brasília, 2012. Disponível em: <http://bd.camara.gov.br/bd/bitstream/handle/bdcamara/11695/ orcamento_publico_silva.pdf?sequence=1 > Acesso em: 30 nov. 2014.

SouzA, Celina. Estado da arte da pesquisa em políticas públicas. In: Hochman, Gilberto; ARRetChe, Marta; MARques, Eduardo (org). Políticas públicas no Brasil. Rio de Janeiro: Fiocruz, 2007.

Flavio Rosendo dos Santos

Mestre em Planejamento e Governança Pública pela Universidade Tecnológica Federal do Paraná. Atualmente é Procurador do Estado do Paraná da Procuradoria Geral do Estado do Paraná.

Contato: flaviorosendosantos@bol.com.br

Andréa Roseli Moreira Cruz Jankoski

Mestre em Planejamento e Governança Pública pela Universidade Tecnológica Federal do Paraná. É servidora pública da Universidade Federal do Paraná desde 1992. Contato: andrea.jankoski@ufpr.br

Antonio Gonçalves de Oliveira

Doutor em Engenharia de Produção pela Universidade Federal de Santa Catarina (UFSC). Atualmente é Professor Associado da Universidade Tecnológica Federal do Paraná (UTFPR) Departamento Acadêmico de Gestão e Economia (DAGEE) vinculado à Graduação e à Pós-Graduação - Programas de Mestrados em Planejamento e Governança Pública (PPGPGP) e Administração (PPGA). Contato: agoliveira@utfpr.edu.br

Vanessa Ishikawa Rasoto

Doutora em Engenharia da produção - Gestão de Negócios pela Universidade Federal de Santa Catarina (2006). Atualmente é Vice-Reitora, professora permanente do mestrado do Programa de Pós-graduação em Planejamento e Governança Pública e professora Titular da Universidade Tecnológica Federal do Paraná (UTFPR).

Contato: vrasoto@hotmail.com 